\title{
Erratum to: A novel mutation of the $L M N A$ gene in a family with dilated cardiomyopathy, conduction system disease, and sudden cardiac death of young females
}

\author{
Wenting Chen $\cdot$ Jianhua Huo $\cdot$ Aiqun Ma
}

Ling Bai $\cdot$ Ping Liu

Published online: 19 July 2013

(C) Springer Science+Business Media New York 2013

Erratum to: Mol Cell Biochem

DOI 10.1007/s11010-013-1734-3

In the original article, Fig. 2 was not correctly displayed.

We now print the complete and correct version of Fig. 2.

Everything else in the article remains correct.

The online version of the original article can be found under doi:10.1007/s11010-013-1734-3.

W. Chen $\cdot$ J. Huo $\cdot$ A. Ma $\cdot$ L. Bai $\cdot$ P. Liu ( $ه)$

Department of Cardiovascular Medicine, First Affiliated

Hospital of the Medical College of Xi' an Jiaotong University,

No. 277 Yanta West Road, Xi'an 710061, Shaanxi,

People's Republic of China

e-mail: pingdoctor@163.com

W. Chen

Department of Cardiovascular Medicine, Suzhou Municipal

Hospital, Suzhou, People's Republic of China 
Fig. 2 Complete pedigree of family with a T510Y frameshift mutation. Squares represent males; circles represent females; filled symbols indicate DCM; half-filled symbols with points represent symptomatic mutation carriers; quarter-filled symbols with points represent asymptomatic mutation carriers with a first-degree AV block; symbols with points represent asymptomatic mutation carriers; crossed symbols represent SCD; blank symbols represent normal subjects

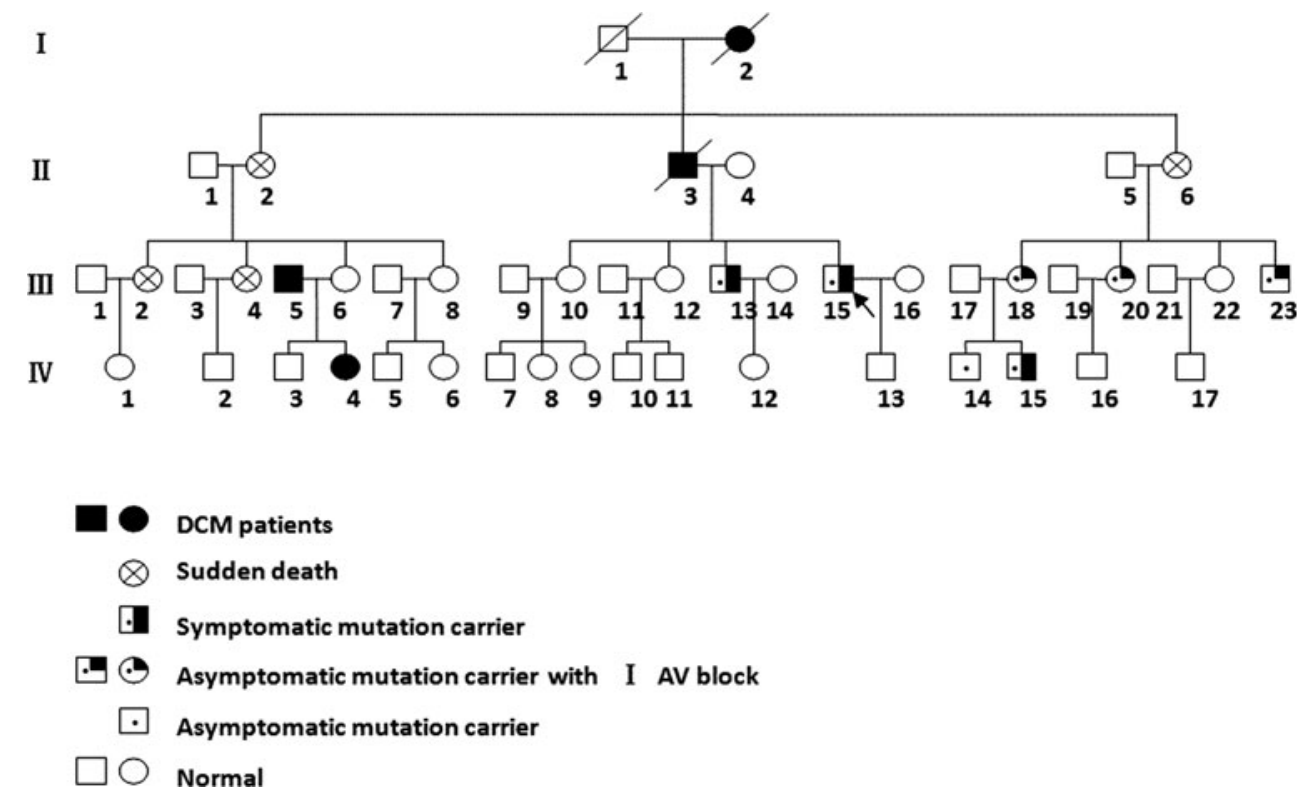

